\title{
TECNIFICAÇÃo DA VIDA: UMA DISCUSSÃO SOBRE O DISCURSO DA MEDICALIZAÇÃO DA SOCIEDADE ${ }^{\star}$
}

Jurema Barros Dantas $\star \star$

\begin{abstract}
Resumo
Neste artigo pensaremos a noção de medicalização da sociedade e da existência cotidiana como um discurso de "tecnificação" da vida. Aderida a uma crença quase absoluta no discurso técnico, a contemporaneidade parece se anestesiar com as descobertas de substâncias que prometem solução para todos os problemas. O medicamento se apresenta como um possivel exemplo desse aparato que, baseado em alta tecnologia, promete o alcance de um bem-estar pessoal e social. Este discurso "tecnificante" da vida se apresenta quase como discurso mítico, onde a apreensão da realidade se dá através de uma narrativa cuja eficácia é determinada pela potência misteriosa das substâncias.
\end{abstract}

Palavras-chave: ciência; técnica; medicalização.

\section{TeChNiCITY OF THE LIFE: A DISCUSSION ABOUT THE DISCOURSE OF MEDICALIZATION IN SOCIETY}

\begin{abstract}
In this article, we intend to address the notion of medicalization in society as well as the everyday existence as the speech of "technicity" of life. Contemporaneity, subscribed to an absolute belief in technical discourse, seems to be in a state of anesthesia with the findings of substances that assure solutions to almost all our problems. The pharmacologic arsenal, provided by the pharmaceutical industry, keeps promising personal and social wellness. We believe this "techniclike" discourse about life is presented as a mythic-magic one, where apprehension of reality is attained by a narration whose efficiency is determined by a mysterious power.
\end{abstract}

Keywords: science; tecnique; medicalization.

\footnotetext{
^ Pesquisa de doutorado realizada no Programa de Pós-Graduação em Psicologia Social da Universidade Estadual do Rio de Janeiro e financiada pela Fundação de Amparo à Pesquisa do Estado do Rio de Janeiro/ FAPERJ.

$\star \star$ Psicóloga, doutoranda em Psicologia Social pela UERJ, Mestre na área de Estudos da Subjetividade pela UFF, Especialista em Psicologia Clínica pelo IFEN/RJ, Pesquisadora Capes na área de Filosofia e Clínica.

E-mail: juremadantas@ig.com.br.
} 
A experiência de dor, desassossego e inquietude.. é provavelmente tão antiga como a história do gênero humano. E atravessa cada existência do princípio ao fim. Não menos antiga e constante é a busca de soluções, remédios, cura... O urgente é curar.

\section{Adriano Amaral de Aguiar}

Nossa análise nasce de uma tentativa de discutir o papel do medicamento na contemporaneidade enquanto objeto mergulhado na desmesura tecnológica. Objeto que a modernidade consagrou e que as novas tecnologias multiplicam com extrema sofisticação. Acreditamos que nosso horizonte histórico entende o corpo humano como uma configuração orgânica condenada ao adequado uso de determinadas substâncias que aparecem como salvadoras. Acreditamos também que os avanços tecnológicos pretendem ultrapassar a própria condição humana através de saberes hegemônicos que, para além da organicidade e materialidade do corpo humano, procuram superação em ideais artificiais, virtuais e imortais. A tecnologia, com seus discursos e saberes, parece nutrir as almas e os corpos contemporâneos.

As pretensões absolutizantes das ciências naturais parecem nortear este projeto moderno de compreensão da subjetividade humana enquanto tecnificação, reduzindo-a a um complexo de sistemas neuronais que, quando em desequilíbrio, origina o processo de adoecimento. A suposta eficácia das medicações mostra-se como uma comprovação do entendimento da subjetividade enquanto engrenagem, que cabe consertar ou ajustar.

O uso abusivo de medicamentos na atualidade parece ser um dos traços significativos de nossa cultura ocidental, na qual impera a convicção de que o mal-estar, bem como o sofrimento de todo gênero, deve ser abolido a qualquer preço. A medicalização da vida tem se tornado cada vez mais, na sociedade ocidental moderna, um dos caminhos mais eficientes e rápidos para amenizar o sofrimento psíquico e os problemas que nos assolam cotidianamente. Neste sentido, o psicofármaco aparece como uma solução técnica para eliminar nossas inquietações, diante de uma sociedade que nos impõe a necessidade de estar na condição de felicidade permanente.

O tema da medicalização, bem como o aumento do uso indiscriminado de psicofármacos, nos chamou a atenção a partir do gritante contraste entre o desenvolvimento tecnológico de última geração e a constatação da existência de um sentimento crescente de vulnerabilidade da vida. Estudar a noção de medicalização da sociedade e da existência cotidiana como um discurso de "tecnificação" da vida constitui-se o tema central deste artigo e uma indagação necessária para a psicologia.

Pensamos a medicalização não como evento isolado a ser previamente definido, mas sim, como um conjunto de práticas que acabam consolidando o medicamento como uma resolução rápida para todo e qualquer problema da vida na atualidade. Este artigo tem como material enriquecedor a minha pesquisa de doutorado que apresenta como um dos seus objetivos a realização de um trabalho 
de campo envolvendo cinco Serviços de Psicologia Aplicada (SPA) de universidades públicas e particulares no Rio de Janeiro. Apesar de termos, no momento, uma análise parcial dos dados, estes se mostraram muito significativos. Foram entrevistados, a partir de um roteiro semi-estruturado aprovado pelo Comitê de Ética da Universidade do Estado do Rio de Janeiro, dez usuários de cada instituição envolvida, escolhidos aleatoriamente seguindo somente a exigência de serem maior de idade. Foram entrevistados usuários que já se encontravam em atendimento ou que estavam indo ao SPA pela primeira vez. A análise das entrevistas foi realizada com base na Fenomenologia, buscando-se explicitar as estruturas significativas de sentido em torno da questão central da pesquisa: o modo pelo qual o discurso acerca da medicalização se apresenta na atualidade.

A faixa etária de nossos entrevistados foi bem variada, no público feminino tivemos pessoas entre 19 e 69 anos e no público masculino tivemos pessoas entre 18 e 35 anos. Das cinquenta pessoas entrevistadas, somente 4 eram do sexo masculino. A procura por um atendimento nos Serviços de Psicologia Aplicada se dava por várias razões, contudo as mais significativas foram problemas de relacionamento, ansiedade e depressão.

Dos cinquenta entrevistados, 48 fazem uso de medicamento e apenas dois buscam outras alternativas nos tratamentos naturais. Dessas 48 pessoas, 44 usam medicamentos em geral, sobretudo analgésicos, e 40 fazem uso de psicotrópicos. Vale ressaltar que cinco já pensaram em fazer uso de psicotrópicos mas alegam ter medo da dependência, quatro fazem uso dos chamados calmantes naturais, como o Pasalix, e dois usam remédios para emagrecer. Nos parece que esses dados embasam a relevância do tema e justificam a importância do mesmo para o campo da psicologia.

Acreditamos que discutir a noção de medicalização da existência cotidiana como um discurso de "tecnificação da vida" nos possibilita problematizar o nosso olhar sobre o tema e, sobretudo, uma época em que o indivíduo encontra-se dominado pelo instrumental e pelo funcional. Mergulhado numa visão racional e objetivista, torna-se fácil creditar a solução de nossas inquietações existenciais às promessas do aparato tecnológico. A contemporaneidade, aderida a uma crença quase absoluta no discurso técnico, parece anestesiar-se com as descobertas, cada vez mais recentes, de substâncias que prometem desde a perda de peso até a felicidade.

O indivíduo, aparentemente livre e soberano, parece ter se reduzido a uma marionete que realiza espasmodicamente os comportamentos que lhe são sutilmente impostos pelo campo sociocultural. A noção de "vida boa", "vida feliz" acabou sendo construída a partir das noções de sucesso, status e dinheiro fornecidas pela lógica capitalista como formas de concretização de uma vida estável e equilibrada. $\mathrm{O}$ arsenal farmacológico, fornecido pela indústria farmacêutica, parece ser um grande aliado para o alcance deste estado de bem-estar pessoal e social.

Inseridos nesta panaceia de práticas e discursos, encontramos todo um aparato tecnológico que fortalece o discurso da medicalização como uma espécie de divindade personificada em pílulas capazes de proporcionar intensas sensações 
ou realizar nossos maiores desejos. O discurso técnico vai, assim, rompendo as paredes das indústrias farmacêuticas e se tornando um discurso comum, quase necessário, para aquele que busca sucesso e felicidade no mundo contemporâneo.

Entendemos assim que o discurso "tecnificante" da vida aparece como discurso mítico, em que a apreensão da realidade se dá através de uma "narrativa fabulosa" cuja eficácia parece ser determinada por uma potência misteriosa, e está oculta em elementos naturais ou sobrenaturais. O discurso da medicalização surge então como um discurso cuja permanência na realidade se dá de forma mítica e mágica.

Neste mundo desencantado, dominado pelo funcional e pelo império da razão calculadora, ao homem restaria, segundo Japiassu (2005), apenas um destino: a crença num pensamento mágico, uma espécie de divindade identificada com um poder mais ou menos personificado, governando tudo o que existe no universo e determinando, uma vez por todas, o curso geral dos acontecimentos e o desenrolar da história humana individual e coletiva.

O mito, segundo Cassirer (2006), pode ser visto como forma de indagação sobre o significado do mundo e da existência humana. $\mathrm{O}$ mito é a mais antiga forma de conhecimento, de consciência existencial e, ao mesmo tempo, de representação sobre a origem do mundo, sobre os fenômenos naturais e a vida humana. Deriva do grego mythos, palavra, narração ou mesmo discurso, e dos verbos mytheyo (contar, narrar) e mytheo (anunciar e conversar). Assim, podemos entender o mito como uma das possibilidades de se explicarem as causas primordiais que impuseram ao homem as suas condições de vida e seus comportamentos; como uma das primeiras manifestações de sentido para o mundo.

O próprio discurso técnico-científico, enquanto um dos discursos sobre o mundo, pode ser visto como um mito, quando somos levados a acreditar que ele é feito à margem da sociedade e de seus interesses, que mantém total objetividade e que é neutro. Segundo Japiassu (2005), o discurso científico, no nosso caso o discurso da medicalização, pode assemelhar-se ao discurso mítico quando o horizonte de sentido desvelado refere-se justamente a disseminação de uma cultura que exalta os efeitos dos fármacos, promovendo a crença de que para tudo na vida há um remédio e que essas fórmulas foram desenvolvidas unicamente para facilitar a vida dos indivíduos.

O medicamento, enquanto produto precioso legitimado pelo aparato tecnológico, pode ser visto como um instrumento dotado de divindade e eficácia para enfrentar quase todos os nossos problemas. Nesse sentido, a crença excessiva e, até certo ponto, ingênua no poder dos medicamentos, ao lado da crescente oferta e indicação desses produtos, com vigoroso suporte da mídia, tendem a aproximálos da condição de fetiche inanimado da atualidade, encarnando o poder sacralizado da ciência e da tecnologia sobre a vida dos mortais. Os médicos também podem ser vistos como intérpretes do divino e detentores das explicações capazes de "controlar" a sociedade com seus conhecimentos. Podemos entender que o mito cria uma compensação simbólica e imaginária para dificuldades, tensões e 
lutas reais tidas como insolúveis; o mito se refere a esse fundo invisível e tenso e o resolve imaginariamente para garantir a permanência da organização social. Rocha (2006, p. 7), em seu livro O que é mito, nos diz que:

O mito é uma narrativa. É um discurso, uma fala. É uma forma de as sociedades espelharem suas contradições, exprimirem seus paradoxos, dúvidas e inquietações. Pode ser visto como uma possibilidade de se refletir sobre a existência, o cosmos, as situações de "estar no mundo" ou as relações sociais.

Em busca de uma organização social e manutenção da ordem, o fenômeno da medicalização da sociedade contemporânea parece sustentar um ideário em que os medicamentos representam concentrados das principais características que os indivíduos devem apresentar para sobreviver em meio à cultura de consumo na atualidade.

O discurso da medicalização, enquanto um discurso mítico, pode ser pensado também a partir da ideia, apresentada por Rocha (2006), de que o mito carrega consigo uma mensagem que não está dita diretamente. Uma mensagem cifrada, ou seja, o que o mito procura dizer não está explicitado literalmente, no entanto, possui um valor e uma eficácia na vida social. Assim, Rocha (2006) coloca em cena um ponto essencial em nossa discussão, a ideia de que o mito pode ser efetivo e, portanto, verdadeiro como estímulo forte para conduzir tanto o pensamento quanto o comportamento do ser humano ao lidar com realidades existenciais importantes.

Podemos pensar, então, o discurso da medicalização como uma narrativa que se propõe verdadeira acerca dos nossos sentimentos e comportamentos, bem como pode promover transformações na vida social. O discurso da medicalização nos contempla, nos seduz, traz respostas e alívio.

O discurso mítico não possui sólidos alicerces de definições, não possui verdade eterna, é como uma construção que não repousa no solo. Segundo Rocha (2006), o discurso mítico flutua, pois seu registro é o do imaginário. Seu poder é a sensação, a emoção, a dádiva e é exatamente neste limiar que podemos situar o discurso da medicalização como construtor de um imaginário social imune de mazelas e sofrimentos, pautado em prazeres e caprichos. Do mesmo modo que o discurso mítico, o discurso da medicalização pode ser visto como uma narrativa através da qual a sociedade se expressa, indica seus caminhos, discute consigo mesma.

Como mito, segundo Pesavento (1999), um discurso trata-se de uma estrutura narrativa que não somente conta e explica, mas revela e porta sentidos outros para além do que é dito. O mito, bem como a medicalização, traz alento a todos nós, muitas vezes trazendo verdades consoladoras e redentoras. Assim, segundo Birman (2001, p. 249), "o sujeito busca, pela magia das drogas, se inscrever na rede de relações da sociedade do espetáculo e seus imperativos éticos". 
Nesse discurso que propaga quase o poder mítico dos medicamentos, "não é mais necessário localizar uma origem patológica para os sintomas: basta apenas conferir a sua distância com relação ao padrão normal" (SIBÍLIA, 2003, p. 191) para que seja prescrito um tratamento baseado nas "novas tecnologias disponíveis no mercado". Nesse sentido, os remédios se prestam à resolução de toda e qualquer disfunção ou inadequação orgânica ou psíquica:

$$
\begin{aligned}
& \text { não se pretende mais a cura, no sentido clássico da medicina } \\
& \text { clínica, mas apenas a regulação do mal-estar. Por isso mesmo } \\
& \text { o medicamento se transforma no [...] eixo da regulação } \\
& \text { corpórea. Assim a leitura do mal-estar corpóreo assume } \\
& \text { uma direção totalmente funcional e não mais etiológica. } \\
& \text { (BIRMAN, 2001, p. 185) }
\end{aligned}
$$

Desta forma, os medicamentos se tornam "fórmulas mágicas" promotoras de inúmeros benefícios capazes de reverter qualquer problema, incômodo ou mal-estar e isentam de riscos o organismo humano. O discurso da medicalização pretende explicar os nossos modos de estar no mundo, de modo a proporcionar soluções imediatas para todos os nossos problemas.

Percebemos em tal discurso a tentativa de explicar nossos comportamentos de modo a veicular modelos a serem seguidos. Modelos míticos que não podem ser questionados, mas apenas seguidos. Consumimos medicamentos que materializam essa divindade em busca do perfeito, do absoluto e da eternidade. Sendo assim, é possível afirmar que a medicalização da sociedade contemporânea aproxima-se de um discurso mítico na medida em que pode ser pensado como um artifício associado a interesses econômicos e, de certa forma, políticos, do sistema em vigor.

Enquanto a subjetividade vem sendo reduzida a uma função biológica, que promete descrever os modos de ser e estar no mundo em termos de equilíbrio químico, o medicamento, neste mesmo contexto, se apresenta sob as mais diversas formas e conteúdos enquanto possibilidade concreta de realização dos ideais contemporâneos.

\section{Medicalização: uma Panaceia Para os PROblemas da Vida}

Seria ótimo, não é mesmo? Dispor de um remédio infalível - um recurso como o nepentes homérico ou a flauta mágica - , capaz de afastar com um sopro as nuvens negras e as preocupações que assombram a mente, inundando-a suavemente de um bem-estar indizível, como nos melhores dias de nossas vidas.

\section{Eduardo Giannetti}

Se o discurso mítico podia explicar os fenômenos através de um pensamento mágico, o discurso da medicalização parece poder explicar a subjetividade por doses químicas e substâncias eficientes, capazes de atender nossas demandas num 
passe de mágica. A aderência a esse discurso da medicalização parece apontar para uma falta de indagação e crítica social acerca dessas verdades sobre nossas emoções e sensações, vendidas em caixas bonitas, em qualquer esquina, a qualquer tempo.

Se o mito fora considerado em determinada época, segundo Gottschall (2004), uma imagem distorcida do mundo onde este só poderia ser captado pelas lentes da ciência, por que não podemos pensar que o discurso da medicalização pautado nesta mesma ciência não é uma imagem distorcida, porém lucrativa e formatadora da realidade? $\mathrm{O}$ que produzimos quando lançamos mão desse discurso da medicalização?

Acreditamos que, em última instância, produzimos uma existência fragilizada que, mergulhada no impessoal, utiliza o ruído dominante das atividades ininterruptas e o embotamento das mais diversas drogas ou tranquilizantes.

Circunscrita por discursos e saberes, que dela fazem um sintoma, a existência parece se tornar facilmente objeto de medicação, em que tais discursos amparados nas neurociências prometem decifrar o funcionamento do cérebro e assim explicar a subjetividade humana. Nossas questões existenciais são vistas como "sofrimentos" que devem ser aliviados por terapias, medicamentos ou distrações vultuosas nesta rede de consumo e novidades instantâneas e intermitentes que pretendem agradar todos os gostos.

Quando o maquinismo em questão ameaça falhar ou, então, entra decididamente em pane, os psicofármacos teriam a finalidade de equilibrar e reajustar o sistema em ruptura, pela introdução dos mediadores neuroquímicos, os únicos capazes, pois, de restaurar a alquimia dos humores perturbados. (BIRMAN, 2001, p.51)

O mercado vende constantemente fórmulas variadas para se evitarem as mínimas possibilidades de sofrermos. Devemos viver um estado permanente de felicidade. A medicina, com seu aparato tecnológico, vai aos poucos se tornando mais um bem de consumo e o vocabulário médico transborda as fronteiras da ciência e da saúde, invadindo nossa linguagem cotidiana. Vemos, na atualidade, a medicina e seus medicamentos protagonizando promessas infinitas de juventude e bem-estar.

A medicalização da sociedade, expressão que demonstra a tendência a se considerar as dificuldades da vida como problemas médicos, solucionáveis através de medicamentos, é uma consequência deste mito de que a farmacologia, apoiada na química e na biologia, dispõe de pílulas e de métodos capazes de enfrentar, se não todas, a grande maioria das doenças e dos problemas cotidianos.

Os progressos da ciência moderna parecem fazer avançar, triunfantemente, o projeto do homem de tornar-se efetivamente soberano sobre a natureza. A ciência moderna, cujo apogeu é alcançado com a teoria positivista do século XIX, tem sua identidade orientada para a dominação e a manipulação dos fenômenos, e confere ao homem poder efetivo sobre a natureza e a imposição do saber domi- 
nante. Segundo Pechula (2007), tal saber sofre um impulso nas primeiras décadas do século XX com o advento das descobertas científicas que proporcionaram o desenvolvimento da tecnologia, dando início à chamada "revolução tecnológica".

O conhecimento científico não é o único, nem absoluto, entretanto, dada sua característica básica, sustentada pela teoria científica, é aquele considerado mais legítimo e verdadeiro. Um conhecimento válido capaz de responder às nossas demandas diárias. Assim, acreditamos que a credibilidade no conhecimento científico abre espaço para um pensamento mágico feito de encantamentos, mitos e verdades parciais na tentativa de anestesiar nossas angústias existenciais, notadamente as que dizem respeito ao nosso futuro.

Percebemos também que a revolução tecnológica possibilitou amplos avanços da informação, o que tornou a divulgação científica mais acessível ao público que excede os limites do meio acadêmico. Os meios de comunicação passaram a alcançar rapidamente a casa dos ouvintes, telespectadores e consumidores, permitindo um grande trânsito de informações acerca de boa parte das grandes descobertas e criações das ciências no mundo atual.

A divulgação das principais descobertas e dos avanços tecnológicos veiculada pelos meios de comunicação de massa ampara-se na fundamentação científica. Em seu nome, esses meios divulgam o conhecimento, instigando o imaginário de que a ela cabe a resolução dos problemas, especialmente, daqueles que envolvem a sobrevivência da humanidade. Segundo Díaz (1996, p. 13), “o imaginário social é uma complexa rede de relações entre discursos e práticas sociais", instalando-se nas distintas instituições que compõem a sociedade e atuando em todas as instâncias sociais. De acordo com este autor, o imaginário é fomentado pelos meios de comunicação de massa. Neste sentido, a informação científica, divulgada por esses meios, alimenta o imaginário de que o conhecimento científico é, entre outros, o mais digno de "crença", aceitação e confiança.

O imaginário coletivo seria, segundo Díaz (1996), fruto dos valores conhecidos e compartilhados numa determinada época e, neste sentido, podemos afirmar que a divulgação científica sustenta um determinado modelo de imaginário social sobre a ciência e, consequentemente, sobre o uso de medicamentos na atualidade. Um modelo que constrói a idéia de ciência enquanto um conhecimento pronto e solucionador da vida cotidiana. Um modelo que busca, em nossa sociedade dominada por uma visão tecnocientífica do mundo, legitimar o discurso da ciência encontrando nele subsídios que revelem os modos de ser e estar adequados ao nosso convívio social.

$\mathrm{Na}$ continuidade dessas palavras, podemos dizer que compartilhamos da apresentação que autores como Gilbert Durand (2002) e Mircea Eliade (2006) fazem acerca do imaginário social. Resguardando as características de cada autor, ambos se baseiam numa perspectiva neoplatônica em que as imagens e o imaginário são sinônimos do simbólico, pois as imagens podem ser entendidas como formas que contêm sentidos afetivos universais cujas explicações remetem às estruturas biopsíquicas e sociais da espécie humana. Para Durand (2002) encontramos na modernidade a permanência dos símbolos arquetípicos das sociedades 
industriais contemporâneas. Nessas sociedades modernas, subsiste a continuidade das grandes imagens míticas nos objetos mais comuns do cotidiano. Podemos entender, então, que dado o seu caráter sincrético, o símbolo, para esses autores dessa tradição neoplatônica, fala por si mesmo e conduz os indivíduos a reminiscência de um sentido primordial que é constitutivo da imagem simbólica.

Pensando imaginário e símbolo como sinônimos que emergem a partir de uma gama de significados históricos e culturais que os indivíduos atribuem a esses símbolos, percebemos o medicamento como pertencente a um imaginário social que acredita encontrar as respostas mais seguras para suas inquietações existenciais neste mundo dominado pelo império da razão calculadora e pelo monoteísmo do mercado, em que o indivíduo livre e soberano parece realizar automaticamente e sem maiores indagações os comportamentos que lhe impõe o campo sociocultural - como ganhar dinheiro, consumir, gozar ou ser feliz com ajuda farmacológica.

Baczko (1985) acredita que o social produz-se através de uma rede de sentidos, de marcos de referência simbólicos por meio dos quais os homens se comunicam, se dotam de uma identidade coletiva e designam as suas relações com as diversas instituições sociais. A vida social é produtora de valores e normas e, ao mesmo tempo, de sistemas de representações que as fixam e traduzem. Sendo assim, corroboramos com Baczko (1985, p. 311) quando ele diz que "O imaginário social torna-se inteligível e comunicável através da produção dos discursos nos quais e pelos quais se efetua a reunião das representações coletivas numa linguagem". É exatamente esse imaginário como processo criador que reconstrói ou transforma o real que colocamos em cena nesse artigo. Entendendo transformar não como uma modificação concreta da realidade, mas como uma certa tradução mental dessa realidade.

Logo, não se trata de descobrir uma verdadeira essência para a questão da medicalização no contemporâneo, nem tampouco apontar suas supostas filiações ocultas. A constituição deste nosso campo de indagação no contemporâneo se dá como efeito e atualização de forças heterogêneas que não só atuam no campo da medicalização, mas também constituem nosso tecido social mais amplo. $\mathrm{Na}$ realidade queremos pôr em questão a construção e a difusão de um imaginário social acerca dos produtos medicamentosos, aparentemente, atravessado por essa profunda modificação sócio-cultural de nosso momento histórico. Seguindo as contribuições de Durand (2002), podemos entender o discurso da medicalização como o mito dominante de nossa época atravessado por atualizações e potencializações sucessivas; bem como, podemos considerar o medicamento seu vigoroso símbolo, ou melhor, um representante fiel dessa lógica tecnificante, em que todo esse imaginário mobilizador e evocador exprime-se e existe.

Esse imaginário se desvelou nas entrevistas realizadas quando aqueles que fazem uso do medicamento esperam resultado rápido (27), melhora (19), alívio (13), cura (11), tranquilidade (6) ou equilíbrio (2); quando 43 entrevistados acham que não tomam muitos medicamentos e apenas sete apresentaram um discurso de inquietação no que se refere à quantidade de medicamentos que usam. 
E, sobretudo, quando, dos 50 entrevistados, 49 acreditam que o remédio é necessário porque há situações nas quais o seu uso é indispensável (21), porque o remédio existe para nos ajudar (9), porque acham que o remédio alivia a nossa dor (8), porque ele serve para nos curar (6), porque não há necessidade de sofrer se existe o remédio (2), porque nos ajuda a suportar a vida (2), porque ele é uma solução (2) ou porque pode trazer o equilíbrio (1). Essa riqueza de dados demonstra parcialmente a força e a presença desse imaginário social acerca do fenômeno da medicalização.

\section{Medicamento e Contemporaneidade}

Nossa contemporaneidade, segundo Dunley (2005), encontra-se marcada pelo acontecimento tecnológico. De acordo com Ewald (2003), todo este arsenal de tecnologia, que aparece gradativamente no decorrer do século XIX, está envolto na ideia de um admirável mundo novo, o mundo da modernidade. O ideário moderno e a tecnologia prometem produzir bem-estar e felicidade através dos bens materiais, dos objetos que se tornam o sonho de qualquer cidadão/consumidor. E, assim, acabamos por nos aprisionar nos ideais de imortalidade e sucesso presentes nas teias tecnológicas, acreditando que nossa saúde e bem-estar são bens preciosos que se encontram em risco, ameaçados pelo jeito de ser e de viver dos nossos tempos.

Em vez de lidar apenas com as doenças e anomalias estruturais do organismo humano, a medicina parece, segundo Aguiar (2004), querer intervir na criação de novas formas de vida e novos modos de viver já que em nossa época consumista, globalizada e informatizada não há espaço para sofrimento, morte ou doença, como fatores naturais da vida humana. Parece haver espaço, somente, para o consumo desmedido, para a cristalização das diferenças, para a manutenção das ilusões em busca de felicidade, riqueza, juventude eterna e imortalidade. Estamos percebendo que, rapidamente, a saúde e o bem-estar estão se tornando sinônimo do consumo de mercadorias, preponderantemente de medicamentos.

$\mathrm{Na}$ atualidade, em que o indivíduo é completamente responsabilizado por todos os âmbitos de sua vida: suas conquistas, seus sucessos, seus prejuízos, seus problemas, seus fracassos, também se coloca sob sua responsabilidade estar frequentando o mundo da saúde ou da doença. Assim, ele assume integralmente a tarefa de definir a si próprio, se tornando o único responsável por constituir sua personalidade, por alcançar o status social que almeja, por ser feliz, belo e bem-sucedido.

Nesse contexto, os sujeitos se tornam "gestores de si” (SIBÍLIA, 2003), uma vez que cada um deve cuidar de si, assumindo a responsabilidade de buscar sozinho as formas de se livrar de eventuais problemas que venham a perturbálo. No entanto, o indivíduo contemporâneo não está completamente sozinho, a publicidade, de acordo com Nascimento (2003), lhe faz companhia em tempo integral, sendo a mediadora de suas relações com o mundo. Por intermédio dos mais variados meios de comunicação, o indivíduo entra em contato com tudo que o mercado põe à disposição para "melhorar" e ou "facilitar" a vida atual. 
Aprendemos, praticamente sem resistência, os princípios do bom consumidor: comprar e fazer uso dos produtos como meio de resolver problemas. Em prateleiras coloridas, revistas, lojas de departamento e demais estabelecimentos temos contato com as melhores formas de curtir a vida. As soluções instantâneas e as buscas para cauterizar nossos sofrimentos parecem ordenar o viver contemporâneo. Desta forma, a medicalização se apresenta com um "poderoso" meio de ajudar os indivíduos em suas escolhas privadas e de auxiliar os sujeitos a solucionar seus problemas pessoais.

Uma possibilidade é que, com o tempo, a pílula acabe se tornando não mais que uma super droga recreativa - "a droga das drogas". Ela seria totalmente evitada por alguns; utilizada de forma intermitente, com abusos ocasionais, por muitos; e capaz de escravizar por completo a vida de uma minoria. Ela se tornaria basicamente um atalho inocente para o bem-estar subjetivo. (GIANNETTI, 2002, p. 173, grifo do autor)

Assistimos a uma ampliação crescente da intervenção médica no cotidiano da vida das pessoas. A tríade indústria farmacêutica-publicidade-médico parecem prescrever, em larga escala, condutas e receitas que devemos seguir a fim de alcançarmos tranqüilidade e aceitação social. Nascimento (2003, p. 33) nos lembra que "o medicamento tende a ser apresentado como solução mágica e seu âmbito de indicação conhece uma expansão sem precedentes, incluindo uma diversidade cada vez maior de problemas".

Mergulhados numa cultura de consumo em que a principal meta colocada para os indivíduos é "aproveitar a vida", o desfrute da mesma se torna sinônimo de explorar o máximo de oportunidades que conseguir, fazendo uso da maior quantidade possível de produtos e serviços oferecidos pelo mercado. Visando fomentar desejos, as mercadorias são apresentadas, segundo Birman (2001), sob a promessa de proporcionar a seu possuidor experiências prazerosas ou de promover sensações nunca antes experimentadas. Assim, os medicamentos, bem como os bens de consumo em geral, vêm assumindo ao lado do seu valor de uso uma conotação adicional que pode ser designada enquanto um valor simbólico.

De acordo com a lógica da incessante produção de necessidades que rege todos os âmbitos da vida contemporânea, nossas experiências devem ser aproveitadas ao máximo, vividas intensamente, visto que elas podem proporcionar sensações que se esvaem rapidamente. O desprazer, o incômodo, o cansaço, o mal-estar, enfim, qualquer negação que se interponha a uma vida de infinitos prazeres deve ser rapidamente aniquilada. Os indivíduos se tornam cada vez menos tolerantes diante de qualquer ameaça de desconforto. E, é justamente nesse contexto, que os medicamentos são anunciados como mercadorias propiciadoras de prazer, para que os indivíduos possam aproveitar intensamente todos os momentos da vida. Os remédios, no imaginário popular, se tornam subsídios para que os indivíduos possam viver melhor todas as situações de seu cotidiano. 
O modo de desvelamento desta festa tecnológica como bem nos sinalizou Dunley (2005), com suas pretensões científicas e resolutivas, vai adequando-se ao projeto de imortalidade e afastamento de todo "mal-estar", entendendo que, de alguma forma, toda a tragicidade de nossa vida pode ser resolvida através dos triunfos no âmbito da neuroquímica, dos avanços genéticos ou das cirurgias que prometem o corpo perfeito e uma vida sem limites.

\section{Cultura de Consumo e Saúde}

A sociedade de consumo, com suas normas, seus valores e parâmetros efêmeros, aponta mudanças em velocidade acelerada e os indivíduos se veem impelidos a acompanhar estas transformações com a mesma rapidez. Buscamos as novidades mais recentes, os produtos de última geração, as roupas da moda ou a dieta que prometa resultados eficientes em menos tempo. Somos, como nunca, livres para lançar nosso olhar em todas as direções e os limites para este olhar são extremamente elásticos.

Há em volta de nós um espaço imenso de possibilidades de movimentação, mas há também uma planificação de sentimentos e atitudes; um vazio imenso, um vazio de sentido, já que a maioria dos valores que regem a produção social dos indivíduos está em fase de mudança.

Numa sociedade onde o individualismo é constantemente alimentado por uma visão normatizadora que pretende planificar gostos, sentimentos e desejos, vemos a responsabilidade por uma vida saudável e tranquila recair sob o indivíduo. Os medicamentos assumem, neste contexto, o posto de uma das principais mercadorias protetoras da vida dos indivíduos contemporâneos. O mercado, das mais diferentes maneiras, oferece uma gama de produtos que prometem manter os indivíduos e seus bens imunes às vicissitudes da vida - entre os quais estão os medicamentos.

Os medicamentos são fórmulas capazes de proteger e melhorar a saúde, são os heróis da atualidade que, para além da cura das enfermidades, prometem apaziguar e cauterizar nossos sofrimentos. Ao adquirir um determinado medicamento nos tornamos imunes às mazelas do corpo, bem como aos acontecimentos da vida. Os remédios são um fundo de reserva, facilmente manipulado em busca de um bemestar supremo; resultado de um somatório de substâncias salvadoras que indicam os caminhos certos no enfrentamento da vida diária. Nesse sentido, os remédios são divulgados como fórmulas de imunidade, tranquilidade e controle dos problemas. São cápsulas protetoras da vida humana em que o bem-estar proporcionado pela solução medicamentosa se torna um dos principais apelos contemporâneos para a venda de fármacos. Trata-se, de acordo com Aguiar (2004), de converter em problemas de saúde determinadas dificuldades relacionadas à vida dos indivíduos; transformar determinados estilos de vida em necessidades médicas.

Ao viver o culto da modernidade e nela procurar construir sua subjetividade - onde tudo se passa numa velocidade assustadora, onde a individualidade e a competição 
reinam e quem não chegar em primeiro acaba por cair em desgraça - compreendemos a busca que as pessoas empreendem para conseguirem resolver seus conflitos e problemas. (EWALD, 1997, p.52)

Os problemas devem perdurar pelo menor tempo possível, os desgastes do dia a dia devem ser amenizados pelo lazer, pelas terapias alternativas ou pelo consumo de produtos sempre desejados. Neste horizonte as mercadorias também são descartáveis, são constantemente substituídas por exemplares mais novos. A indústria farmacêutica empenha-se arduamente em manter a variedade dos seus produtos e uma tecnologia de última geração.

Os medicamentos assumem a função de magicamente livrar os indivíduos de preocupações e desprazeres, visto que asseguram a saúde e permitem que se curtam, sem medo, todos os prazeres da vida. Nesse sentido, a magia midiática divulga o medicamento como facilitador do angustiante viver contemporâneo, instaurando uma "narcotização da vida" (SOARES, 2000). Isto por que:

Hoje o modelo do que cada um deve ser está ancorado na sua capacidade de extrair sensações do corpo e de corresponder a determinado padrão estético. As pessoas devem ser magras, jovens e viver um estado permanente de felicidade. (AGUIAR, 2004, p. 9).

A publicidade, representante autêntica de uma sociedade de consumo, constrói por meio da erotização dos desejos a importância do indivíduo ser ativo, estar disposto para enfrentar todas as situações cotidianas, e, para auxiliá-lo nessa dura tarefa, nada melhor do que uma fórmula farmacêutica. Ser potente e dinâmico, atendendo a todas as exigências da sociedade, são apenas algumas das várias características dessa necessidade de realizar sempre o melhor, de maneira criativa e prazerosa:

Existir, na nossa sociedade contemporânea, é o resultado de um esforço permanente. E isto para todas as categorias sociais. A reprodução física e social é uma tarefa constante. $\mathrm{O}$ medicamento faz parte integrante deste esquema [...]. Viver, nessa sociedade implica num permanente e ininterrupto cumprimento de tarefas, que inclui até coisas que não são habitualmente vistas como tarefas. É preciso não apenas trabalhar [...]. Mas também dormir, ir a festas, receber amigos, comer, exercer a sexualidade etc. Adoecer nesse contexto, figura como um parêntese nessa exigência. (LEFEVRE, 1991, p. 71).

O mercado de medicamentos, por meio da publicidade, anuncia seus produtos como substâncias auxiliadoras do viver contemporâneo, minimizadoras das terríveis situações cotidianas que batem a nossa porta sem pedir licença. Devemos estar sempre prontos para as mudanças e para as novas tecnologias do mercado. Devemos nos atualizar, se quisermos executar com sucesso tudo aquilo que nos 
exigem. Segundo Lefevre (1991), o medicamento é um recurso fácil e rápido que permite o restabelecimento para qualquer tarefa. Ao mencionarmos a questão da medicalização no contemporâneo, torna-se indispensável demarcar as noções de saúde e doença abordadas no presente texto. Na trajetória evolutiva sobre as concepções acerca da saúde e da doença, poderíamos considerar alguns paradigmas que começam com uma visão mágico-religiosa na antiguidade e terminam com a predominância do atual modelo biomédico.

A saúde fora vista no passado como uma dádiva recebida pelo enlace com as divindades de um modo geral e, consequentemente, a doença era vista como resultado de uma transgressão individual ou coletiva no que se refere às forças sobrenaturais. Foi no contexto do renascimento que as raízes históricas do modelo biomédico predominante hoje se iniciaram. Com as significativas mudanças de ordem técnico-científica ocorridas a partir do século XV, a teoria heliocêntrica, a despeito da força dos dogmas católicos, ganhou expressão. E no século XVI, o filósofo e matemático René Descartes apresentou o que seria a base do que conhecemos hoje como método científico. Desde então, essa certeza de encontrar verdades acerca do viver humano se fortalece a cada dia. A certeza de que, por meio do controle ou da exatidão matemática, podemos oferecer saúde e evitar doenças se propaga ardentemente. Parece então que o fenômeno da medicalização pauta-se no modelo biomédico e se apresenta como uma expressão virtuosa das conseqüências concretas desse modelo reducionista que não se cansa de buscar leis universais acerca do binômio saúde e doença na vida dos indivíduos.

Atualmente estando a noção de saúde norteada pelo olhar biomédico e atrelada à lógica do mercado, ser saudável passa a significar estar sempre ativo, disposto e dando o melhor de si, para, desta maneira, conseguir ser bem- sucedido na execução de múltiplos papéis, sem se descuidar da aparência ou da obtenção de prazer como manda a regra contemporânea. Vivemos sob a lógica da saúde como extensão do mercado e do medicamento como sua valiosa mercadoria. Isto ocorre na medida em que o acesso ao consumo foi convertido no modo principal para obtenção de níveis satisfatórios de bem-estar. A saúde, em síntese, passa a ser vista como possível na estreita relação do acesso às tecnologias de ponta. A eficácia e a efetividade da tecnologia passam a se confundir com a concretude de saúde e bem-estar.

Parecer saudável - belo, magro, jovem e atlético - é uma das muitas exigências que se tornam mais fáceis quando auxiliadas por produtos farmacêuticos. Vivemos sob o primado da aparência e do sucesso a qualquer preço. Nosso corpo, nossa carreira profissional, nossos laços afetivos e, por fim, nossa própria vida, mergulhados nessa lógica da cultura do ter que se torna majoritária sobre a cultura do ser, acabam se tornando peças negociáveis e rentáveis.

Sonhos, utopias e desejos infinitos são fabricados diariamente indicando uma receita que devemos seguir para conquistarmos sempre a vitória e o sucesso. Tais receitas colocam sempre em exposição novas mercadorias oferecidas como garantia de satisfação. São fórmulas "perfeitas" em lindas cápsulas com suas caixas sedutoras que, maciçamente, introduzem no imaginário social a ânsia pela perfeição estética, pela felicidade e pelo sucesso. 
A felicidade e o bem-estar são apelos que surgem como consequência do estabelecimento de todos os outros valores associados à mercadoria. Ao apresentar boa aparência, obter prazer máximo em todos os momentos da vida, não sentir dor, estar tranquilo, entre outras coisas, o indivíduo supostamente se torna feliz. Da maneira mais obvia e frequente, a contemporaneidade promete, através da medicação, felicidade em meio às mazelas existenciais produzidas pelo sistema consumista. Os medicamentos se transformam em elementos mágicos, utilizados ao menor sinal de angústia, tristeza ou qualquer desconforto psíquico.

A partir desta análise, é possível perceber de que forma a noção de saúde foi sendo associada a outros valores, com o fim último de fomentar o consumo das mercadorias que a representam. Nesse sentido, os medicamentos passaram a ocupar um novo lugar no imaginário social, deixando de ser mercadorias simplesmente curativas para se tornarem signos de beleza, felicidade, prazer, tranquilidade, sucesso, ou seja, produtos capazes de adequar o funcionamento fisiológico e psicológico do organismo às exigências consumistas da atualidade.

Os sofrimentos e os dramas existenciais foram absorvidos pela lógica de mercado e transformados numa química a ser ingerida cotidianamente numa maneira "eficiente" e "prática" de resolução dos problemas que atravessam a vida na contemporaneidade.

Escapamos de uma apropriação de si para permanecermos mergulhados na impessoalidade, isto porque o mundo realmente melhorou tecnologicamente, contudo, em vários aspectos, tornou-se aparentemente inóspito para as necessidades humanas. Somos intimados a participar de um mundo em movimento acelerado, imediatista, efêmero, que promove o narcisismo exacerbado e um modo de relação objetivo e específico entre os indivíduos.

Todos estes pontos configuram um mundo vulnerável e fugaz no que se refere aos modos de estar no mundo e aos tipos de relação que se estabelecem com ele. Tendo referências tão fluídas e sensações tão inconstantes, somos provocados pela proliferação de forças que abalam continuamente nossas ilusões identitárias, bem como nossas ilusões de controle sobre o devir. Estas questões, no entanto, não se colocam para um mundo que se pretende definido e disposto segundo as linhas e o compasso da ciência e do poder, já que esta dimensão trágica da vida deveria fazer parte somente das elucubrações filosóficas. Esse modo de configuração do contemporâneo determina os nomes que damos aos nossos medos e angústia, ou às marcas nas quais suspeitamos que resida a ameaça à nossa segurança.

A fragilidade de viver, a certeza do morrer, o fracasso ou o pavor do amor, a fragilidade das relações, a solidão, a vacuidade, a eterna impermanência de tudo: esta é a vida mesma, e não há outra. Esta é a vida que o contemporâneo tenta prever e, por vezes, medicar. Todas as pílulas do mundo, embora possam fazer-nos esquecer essas questões, não poderiam suprimi-las - e ainda menos responder a elas. Compartilhamos o pensamento de Giannetti (2002, p. 177) quando este diz que: "O que não dá para engolir é a idéia de que a felicidade é alguma coisa que você compra, embrulha e leva para casa, como aspirinas ou picolés". 
O modo de pensar contemporâneo parece refutar tais considerações, marcando, através dos recursos tecnológicos e de pesquisas, a intenção de medir os riscos à vida e a ilusão de algum controle sobre a existência.

\section{Considerações Finais}

O discurso veiculado pela indústria da saúde é hoje um dos mais poderosos vetores de produção da subjetividade contemporânea. O discurso médico tem se tornado uma parte importante da vida cotidiana, regulando a maneira dos indivíduos se comportarem, o tipo de alimentação que usam, as atividades que realizam e o modo de entender e experimentar a própria existência. De acordo com Aguiar (2004), este discurso invade a cultura e transforma grande parte da nossa vida diária, na medida em que vende-se cada vez mais aos indivíduos a ideia de que é necessário que eles conheçam e aprendam a utilizar esse discurso.

Em meio a uma vasta literatura sobre saúde e inúmeras fontes publicitárias prontas a atender todos os desejos, assistimos a uma procura cada vez mais ávida, por parte dos indivíduos, por adquirir conhecimentos médicos e produtos de última geração a fim de corresponderem adequadamente aos padrões impostos pela produção da geração "saúde e sem problema".

Nosso cotidiano incorpora diariamente o vocabulário neurocientífico ao modo como experimentamos a vida, como traduzimos nossos próprios sentimentos, motivações e desejos. Trata-se da produção de realidades que, por meio de práticas e discursos, engendra novas maneiras de os indivíduos entenderem, controlarem e experimentarem seus corpos e sentimentos.

Fabricamos facilmente uma receita para o tratamento dos sofrimentos humanos, nos esquecendo que inevitavelmente estes estão ligados às turbulências próprias da vida. Fabricamos o medicamento como uma resposta quase obrigatória e exclusiva em busca da solução mais rápida que nos traga o tão almejado bem-estar. São substâncias artificiais que com suas inúmeras promessas nos oferecem nada menos que soluções também artificiais e paliativas para o bom viver na atualidade. Em busca de alívio, cura e conforto nos privamos daquilo que seria originariamente humano: angústia, culpa, vergonha, tristeza, frustração e consciência de si.

A vida não é uma doença. Viver é viver com todos os riscos. E para esta vida não há Prozac, há experimentação, reflexão e escolha. Nosso propósito com este artigo foi pensar, a partir do viver cotidiano, o imaginário social que envolve a questão da medicalização enquanto um discurso de tecnificação da vida e sua possibilidade de aproximação com o discurso mítico.

Reconhecemos os necessários avanços da medicina, apenas tentamos apontar suas limitações e sua tendência ao reducionismo da experiência humana a uma causalidade química. Nosso objetivo foi tematizar o aprisionamento quase total da vida nas malhas de uma lógica técnica que pretende entender o humano por meio de princípios deterministas. Tivemos a intenção de problematizar nosso campo de práticas e saberes que, no seu modo de funcionar, vêm produzindo no contemporâneo a medicalização da vida. 


\section{REFERÊNCIAS}

AGUIAR, A. A. Psiquiatria no Divã: entre as ciências da vida e a medicalização da existência. Rio de Janeiro: Relume Dumará, 2004.

BACZKO, B. Imaginação Social. In: LEACH, E. et al. Enciclopédia Einaudi: Anthropos - Homem. Lisboa: Imprensa Nacional, 1985. v. 5, p 296-332.

BIRMAN, J. Mal-estar na atualidade. Rio de Janeiro: Civilização Brasileira, 2001.

CASSIRER, E. Linguagem e Mito. São Paulo: Perspectiva, 2006.

DÍAZ, E. (org). La ciência y il imaginário social. Buenos Aires: Biblos, 1996.

DUNLEY,G. A Festa Tecnológica: o trágico e a crítica da cultura informacional. São Paulo: Escuta; Rio de Janeiro: Fiocruz, 2005.

DURAND, G. As estruturas antropológicas do imaginário. São Paulo: Martins Fontes, 2002.

ELIADE, M. Mito e Realidade. São Paulo: Perspectiva, 2006.

EWALD, A. P. As Grandes Exposições e as novas tecnologias da Modernidade. Sociedad y Utopia, Madrid, v. 21, p. 63-73, jan./jun. 2003.

EWALD, A. P. Indústria Cultural e Subjetividade. Sociedad y Utopia, Madrid, v. 9, p. 45-53, jan./jun. 1997.

GIANNETTI, E. Felicidade: diálogo sobre o bem-estar na civilização. São Paulo: Companhia das Letras, 2002.

GOTTSCHALL, C. A. M. Do mito ao pensamento cientifico: a busca pela realidade, de Tales a Einstein. São Paulo: Atheneu, 2004.

JAPIASSU, H. Ciência e Destino Humano. Rio de Janeiro: Imago, 2005.

LEFEVRE, F. O medicamento como mercadoria simbólica. São Paulo: Cortez, 1991.

NASCIMENTO, M. C. Medicamentos: ameaça ou apoio à saúde? Rio de Janeiro: Vieira \& Lent, 2003. 
PECHULA, M. R. A Ciência nos meios de comunicação de massa: divulgação de conhecimento ou reforço do imaginário social? Ciência e Educação, Bauru, v. 13, n. 2, p. 211-222, maio/ago. 2007. Disponível em $<$ http://www.scielo.br/pdf/ciedu/v13n2/v13n2a05.pdf > . Acesso em: 22 nov. 2008.

PESAVENTO, S. J. O Imaginário da Cidade: visões literárias do urbano. Porto Alegre: Universidade, 1999.

ROCHA, E. O que é mito? São Paulo: Brasiliense, 2006.

SIBILIA, P. O homem pós-orgânico: corpo, subjetividade e tecnologias digitais. Rio de Janeiro: Relume Dumará, 2003.

SOARES, J. C. R. S. A autonomia do paciente e o processo terapêtico: uma tecedura complexa. 2000. Tese (Doutorado)-Universidade do Estado do Rio de Janeiro, Rio de Janeiro, 2000.

Recebido em: junho de 2009

Aceito em: setembro de 2009 